\title{
Expression of CD44 on rheumatoid synovial fluid lymphocytes
}

\author{
Dermot Kelleher, Anne Murphy, Nicola Hall, M Bishr Omary, Grainne Kearns, \\ Aideen Long, Eoin B Casey
}

\begin{abstract}
Objectives-To investigate the involvement of the adhesion molecule CD44 in the homing of lymphocytes to synovial tissue, by examining the density of expression and molecular mass of CD44 on rheumatoid synovial fluid lymphocytes.

Methods-Twenty patients with rheumatoid arthritis were studied. Peripheral blood and synovial fluid lymphocytes were isolated by Ficoll-Hypaque sedimentation. CD44 expression was analysed by two colour flow cytometry of $\mathrm{CD} 3$ positive $T$ lymphocytes with calculation of mean fluorescence intensity. Expression of activation markers M21C5, M2B3, interleukin (IL)-2 receptor and transferrin receptor was quantitated. In addition, CD44 molecular mass was examined by Western blot in six patients.
\end{abstract}

Results-CD44 expression was markedly increased on synovial fluid $T$ lymphocytes of rheumatoid patients relative to peripheral blood lymphocytes from the same individuals. CD44 molecular mass on peripheral blood mononuclear cells was $88 \mathrm{kDa}$, but that on synovial fluid lymphocytes was only $83 \mathrm{kDa}$. CD44 expression correlated significantly with expression of activation markers M21C5, M2B3, and the IL-2 receptor.

Conclusions-Alterations in density of expression or of the molecular mass of CD44 could contribute to local tissue injury, either directly by facilitating adhesion, or indirectly through effects on other adhesion molecules.

(Ann Rheum Dis 1995; 54: 566-570)

Several cell surface receptors have been identified as homing receptors for human $T$ cells; these molecules direct the lymphocyte to putative tissue targets. ${ }^{12}$ Antibodies directed against such homing receptors block migration of lymphocytes in a tissue selective fashion in vivo, and also block binding of lymphocytes to high endothelial venules in the target tissue in vitro. ${ }^{34}$ Receptors identified as important in migration of lymphocytes to the synovium in mouse models include the molecules lymphocyte function associated antigen (LFA)-1 $(\mathrm{CD} 11 \mathrm{a} / \mathrm{CD} 18)^{1}$ and phosphoglycoprotein (Pgp)-1 (CD44). ${ }^{5}$ These molecules may both be blocked by inhibitory antibodies which prevent migration of $T$ cells to the inflamed synovium.
CD44 is a molecule which has been found to be expressed on a wide variety of cells and which possesses differing molecular mass isoforms. ${ }^{6}$ It was first identified as a homing receptor involved in migration to the mouse regional lymphoid organs. More recently, it has been identified as a receptor for hyaluronic acid, although it appears that this molecule may have multiple ligands. ${ }^{7}$ The multiple isoforms expressed by CD44 have been recognised not only on the basis of differential glycosylation, but also by means of alternate splicing of a range of different exons; ${ }^{8}$ expression of alternatively spliced variant forms of the molecule is associated with migration and metastasis of tumour cells. ${ }^{9}$ In a previous study it has been reported that CD44 expression is increased on rheumatoid synovial fluid lymphocytes; however, the nature of the cells expressing increased CD44 was not characterised. ${ }^{10}$

In this study, we have examined the expression of CD44 in synovial fluid CD3 positive $T$ lymphocytes derived from rheumatoid arthritis (RA) synovial fluid and in $T$ lymphocytes derived from peripheral blood of patients with RA. In addition, we have examined the expression of LFA-1 and the activation markers interleukin (IL)-2 receptor, transferrin receptor, and the more recently described monoclonal markers, $\mathrm{M} 21 \mathrm{C} 5^{11}$ and $\mathrm{M} 2 \mathrm{~B} 3^{12}$ on these lymphocytes.

\section{Patients and methods}

PATIENTS

Twenty patients with RA were studied. Peripheral blood and synovial fluid were obtained contemporaneously from RA patients. Mononuclear cells were isolated from blood and synovial fluid by Ficoll-Hypaque sedimentation. Cell yields from synovial fluid ranged from $1.2 \times 10^{6} / \mathrm{ml}$ to $6.5 \times 10^{6} / \mathrm{ml}$ (median $2 \cdot 4 \times 10^{6} / \mathrm{ml}$ ).

ANTIBODIES

Antibodies to CD25 (IL-2 receptor) and to CD4 and CD8 were purchased from Beckton Dickinson. Antibody OKT3 was derived as a supernatant from the hybridoma obtained from the American Type Culture Collection (ATCC). Antibody to LFA-1 was purchased from Monosan, Sanbio bv, Uden, Netherlands. Antibodies M2B3, M21C5 to T cell activation antigens were derived from ascites from respective hybridomas. Antibody L3D1 to CD44, and L1B1 to transferrin receptor were prepared and 
characterised by standard hybridoma technology. The antibodies used in these experiments represent ascites from the respective clones. Antibody Bric 238 to CD44 was a gift of Dr D Anstee, Bristol. All immunofluorescence was performed using monoclonal antibody L3D1 and Western blotting was performed using Bric 238. The negative control antibody for indirect immunofluorescence was a monoclonal antibody recognising murine Class II molecule, IE (ATCC).

\section{TWO COLOUR IMMUNOFLUORESCENCE}

Two colour immunofluorescence was performed according to standard techniques. Briefly, antibodies to the above antigens were incubated for 30 minutes with mononuclear cells derived from blood or synovial fluid, followed by three washes in phosphate buffered saline (PBS)/azide. Fluorescein isothiocyanate (FITC) conjugated second antibody, goat antimouse immunoglobulin (Dakopatts), was then added and incubated for 30 minutes of $4^{\circ} \mathrm{C}$. Cells were washed and blocked with $1 \%$ normal mouse serum, followed by directly conjugated anti-CD3 phycoerythrin (PE), CD4-PE, or CD8-PE. Cells were then washed and resuspended in $\mathrm{PBS} / 1 \%$ paraformaldehyde for counting.

A number of controls were included in all experiments. These included a PE conjugated antibody control (Coulter), and the combination of anti-CD3-PE, followed by anti-IE and FITC-gam. In order to determine the percentage of positive cells, $\mathrm{CD} 3$ positive cells were gated on (fluorescence (FL) 2 channel) and an FL1 histogram was constructed for analysis of fluoresceinated antibodies. The percentage of positive cells was determined by subtraction from the anti-IE control antibody.

Analysis was performed using the Becton Dickinson FACSCAN instrument using Consort 30 software. Cells gated for CD3 positivity were analysed on histograms for the pattern and density of LFA-1 and CD44 expression. Density of expression of any molecule was calculated as the mean fluorescence intensity (MFI) on a logarithmic scale and comparisons between peripheral blood and synovial fluid were run contemporaneously. Data are expressed as arbitrary linearised units derived from Consort 30 software.

IN VITRO MODULATION OF EXPRESSION Lymphocytes from normal individuals were cultivated for three days in vitro in RPMI 1640 medium (Gibco, Life Technologies Ltd, Paisley, Scotland) containing $100 \mathrm{U} / \mathrm{ml}$ penicillin, $100 \mu \mathrm{g} / \mathrm{ml}$ streptomycin, $20 \mathrm{mmol} / / \mathrm{L}$-glutamine and $10 \%$ fetal calf serum in the presence of the $\mathrm{T}$ cell mitogen, phytohaemagglutinin (PHA). After culture, lymphocytes were removed and immunofluorescence staining performed as previously described for LFA-1 and CD44.

IMMUNOBLOT ANALYSIS

Peripheral blood $\mathrm{T}$ cells and synovial fluid $\mathrm{T}$ cells were washed in PBS, $\mathrm{pH} 7 \cdot 2$, centrifuged at $250 \mathrm{~g}$ for five minutes and resuspended in $1 \mathrm{ml}$ of buffer containing $1 \%$ Triton-X-100, $0.5 \mathrm{mmol} / \mathrm{l}$ EGTA, $0.1 \mathrm{mmol} / \mathrm{l}$ phenyl methylsulphonyl fluoride, and leupeptin $10 \mu \mathrm{g} / \mathrm{ml}$. This lysate was gently agitated at $4^{\circ} \mathrm{C}$ for 30 minutes and centrifuged at $200 \mathrm{~g}$ for 10 minutes. The resultant supernatant was then spun at $100000 \mathrm{~g}$ for 30 minutes at $4^{\circ} \mathrm{C}$ using a Beckman L5-50 ultracentrifuge equipped with a SW 41 rotor. Proteins were separated by polyacrylamide gel electrophoresis $(10 \%)$ and electrophoretically transferred to a nitrocellulose membrane. The membrane was blocked using Blotto Tween solution ( $5 \%$ nonfat dried milk $/ 0.05 \%$ Tween 20 ) in PBS at $\mathrm{pH} 7.2$ and then incubated with monoclonal antibody to CD44, Bric 238, and control monoclonal antibody, anti-vimentin, in PBS/ Blotto Tween for 18 hours, followed by biotinylated sheep anti-mouse antibody (one hour) and streptavidin-biotinylated horseradish peroxidase complex in 1\% gelatin for 30 minutes. Immunoreactive bands were visualised by treatment with 3-amino-9-ethylcarbimazole. Molecular weight marker proteins were localised by staining with $0.2 \%$ Ponseau-S in $3 \%$ trichloroacetic acid, $3 \%$ sulphosalicylic acid.

\section{STATISTICS}

Paired Student's $t$ test was used to compare MFI in peripheral blood and synovial fluid lymphocytes. Spearman rank correlation was used to analyse correlation of CD44 and activation marker expression.

\section{Results}

EXPRESSION OF CD44 ON T CELLS FROM RHEUMATOID SYNOVIUM

The pattern of CD44 expression on synovial fluid lymphocytes exhibits a biphasic distribution, with a population of high expressing cells $\left(\mathrm{CD} 44^{\mathrm{hi}}\right)$ and a population of low expressing cells $\left(\mathrm{CD} 44^{\mathrm{lo}}\right)$. On two colour analysis, the $\mathrm{CD} 3$ population was found to lie exclusively within the $\mathrm{CD} 44^{\mathrm{hi}}$ population, indicating that all $\mathrm{T}$ cells in synovial fluid express CD44 in high density (fig 1).

In peripheral blood, CD3 cells expressing LFA-1, similarly formed two populations: one expressed a high density of LFA-1 and a second population expressed a low density of the receptor (fig 2). However, CD3 cells from synovial fluid almost universally expressed LFA-1 as a single peak, intermediate in expression density between the high and low peaks in peripheral blood (fig 2). Table 1 compares the distribution of the biphasic and uniphasic populations of LFA-1 expressing cells between peripheral blood and synovial fluid lymphocytes in RA patients, and shows that the proportions of each population in peripheral blood reflected those found in normal individuals.

In agreement with a previous report, the percentage of CD4 and CD8 positive cells did not differ significantly from that seen in peripheral blood. ${ }^{13}$ Furthermore, neither 


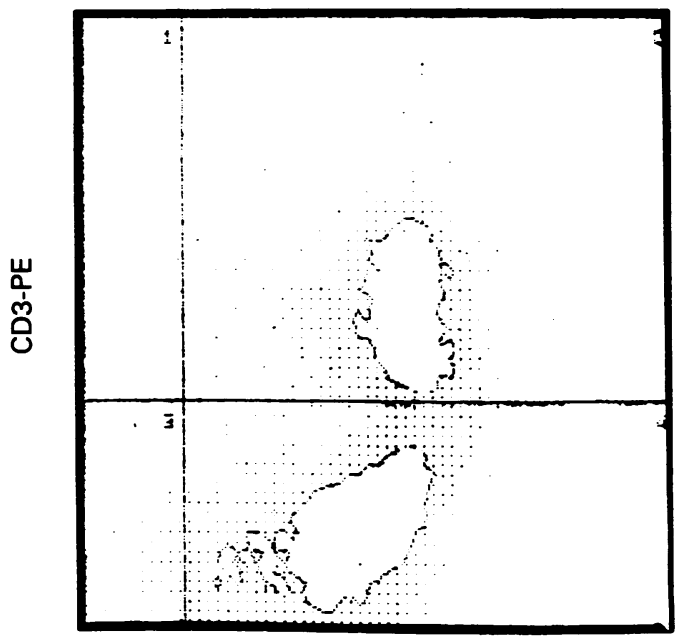

CD44-FITC

Figure 1 CD44 expression on $T$ cells in synovial fluid. Two colour immunofluorescence plot using anti-CD3-PE and indirect immunofluorescence with anti-CD44-FITC. $C D 3$ cells are universally CD44-high.

CD44 nor LFA-1 were significantly increased on CD8 cells relative to CD4 cells in synovial fluid (CD44 177 (SE 22) v 164 (27), $\mathrm{n}=4$; LFA-1 40 (6) $v 37(7), \mathrm{n}=4)$.

IN VITRO EXPRESSION OF CD44 AND LFA-1 Cultivation of lymphocytes for three days increased expression of CD44; activation with PHA did not significantly augment this increase (table 2). However, three day cultivation of lymphocytes with PHA significantly increased the level of LFA-1 expression and converted the biphasic peak to a uniphasic peak (in preparation-data not shown).

Table 1 Expression of LFA-1 on peripheral blood lymphocytes in normal subjects and patients with $R A$, and on synovial fluid lymphocytes in patients with $R A$

\begin{tabular}{lccllll}
\hline & \multicolumn{2}{l}{ Peripheral blood } & & \multicolumn{2}{l}{ Synovial fluid } \\
\cline { 2 - 3 } & Biphasic & Uniphasic & & Biphasic & Uniphasic \\
\hline Normal & 9 & 1 & 3 & 15 \\
RA & 14 & 4 & 3
\end{tabular}

Biphasic $=$ two populations, expressing LFA-1 in either high or low density; uniphasic = one population, having an intermediate density of expression in RA patients (but a low density of expression in normal individuals).

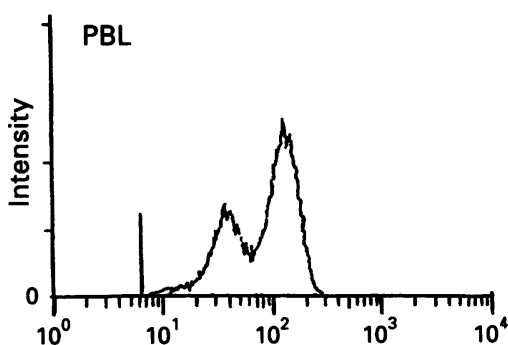

No of cells expressing LFA-1

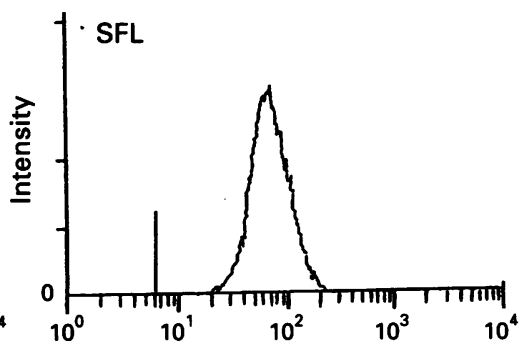

No of cells expressing LFA-1
Figure 2 Number of peripheral blood (PBL) and synovial fluid (SFL) CD3-gated lymphocytes expressing LFA-1 in rheumatoid arthritis.
Table 2 Changes in CD44 expression (measured as mean fluorescence intensity) on peripheral blood lymphocytes on three day culture in the presence or absence of $20 \mu \mathrm{g} / \mathrm{ml}$ phytohaemagglutinin (PHA)

\begin{tabular}{llll}
\hline Expt & \multicolumn{3}{l}{ Mean fluorescence intensity } \\
\cline { 2 - 4 } & Day 1 & Day 3 & Day 3 + PHA \\
\hline 1 & 83 & 266 & 285 \\
2 & 49 & 185 & 157 \\
3 & 94 & 313 & 282 \\
\hline
\end{tabular}

CD44 EXPRESSION DENSITY ON RHEUMATOID SYNOVIAL FLUID LYMPHOCYTES

Figure 3 shows that the intensity of expression of CD 44 was increased in rheumatoid synovial fluid $\mathrm{T}$ lymphocytes relative to those in peripheral blood (mean (SE) MFI 181 (20) $v$ 126 (13); $\mathrm{p}<0.01$ ). CD44 expression was increased in synovial fluid in all but one patient, who had longstanding 'burnt-out' arthritis. The level of expression of CD44 on synovial fluid populations correlated with expression of IL-2 receptor. In those patients in whom M21C5 and M2B3 were estimated $(n=10)$, there was also a correlation between expression of these receptors and CD44 density (table 3). There was no significant difference in MFI of CD44 on non- $T$ cells in peripheral blood compared with synovial fluid (64 (7) $v 71$ (8)).

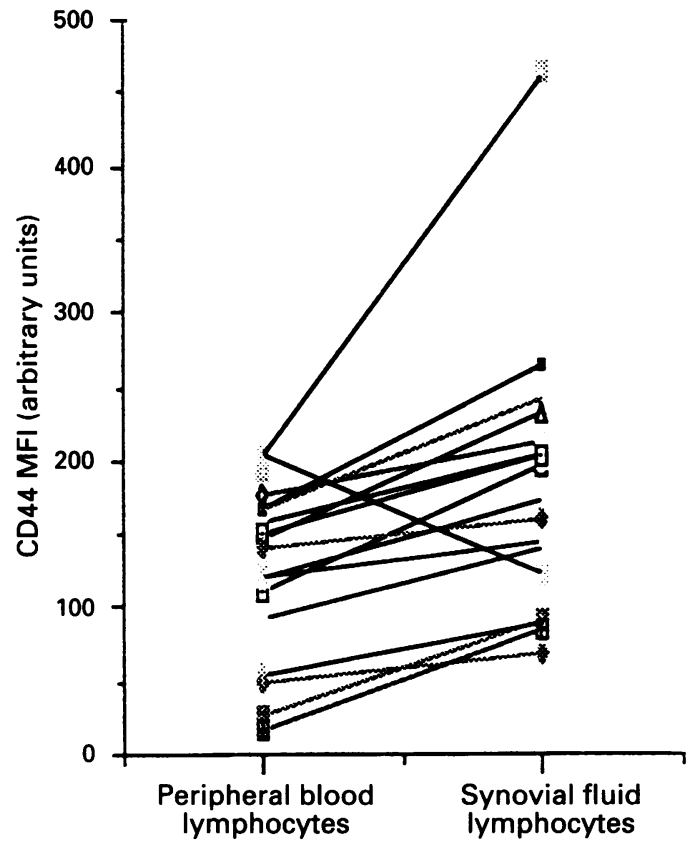

Figure 3 Comparison of CD44 mean fluorescence intensity (MFI) in peripheral blood and synovial fluid of $R A$ patients. CD44 expression is consistently greater in synovial fluid lymphocytes.

Table 3 Expression of activation markers on synovial fluid lymphocytes (SFL) and correlation with CD44 mean fluorescence intensity

\begin{tabular}{llll}
\hline & $S F L(\%)$ & Rho & pt \\
\hline TfR & $37(14)$ & 0.504 & NS \\
IL-2R & $14(5)$ & 0.755 & $<0.025$ \\
M21C5 & $7(1.5)$ & 0.687 & $<0.05$ \\
M2B3 & $13(5.7)$ & 0.898 & $<0.025$ \\
\hline
\end{tabular}

SFL values are mean (SE) percentage of cells expressing the transferrin receptor (TfR), interleukin-2 receptor (IL-2), and markers M21C5 and M2B3. +Spearman rank correlation. 


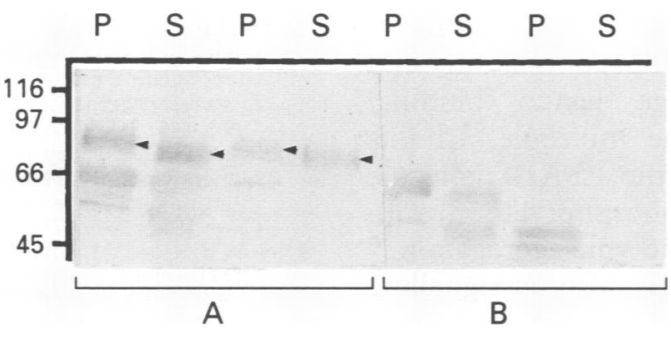

Figure 4 Western blot analysis of molecular weight of $C D 44$ on lymphocytes from peripheral blood $(P)$ and synovial fluid (S) of two patients with $R A$. A: Anti-CD44. B: Anti-vimentin, an isotype control. Specific CD44 species indicated by arrowheads.

MOLECULAR MASS OF CD44 SPECIES

The molecular mass of peripheral blood lymphocyte CD44 species was approximately $88 \mathrm{kDa}$ in all cases (fig 4), but in five of six synovial fluid lymphocyte samples examined, the molecular mass was significantly reduced, to approximately $83 \mathrm{kDa}$.

\section{Discussion}

Both in vivo and in vitro work has suggested that the CD44 molecule is involved in homing of lymphocytes to the synovium. Adherence of cells to endothelial cells in tissue sections of rheumatoid synovium is inhibited by antibody to CD44. ${ }^{5}$ Furthermore, the CD44 molecule is a receptor for hyaluronic acid, a molecule known to be involved in the maintenance of integrity of synovial fluid. A previous study has demonstrated an increase in CD44 expression by synovial fluid lymphocytes, but the nature of the cells expressing high levels of CD44 was not characterised. ${ }^{10}$ Our data indicate that the expression of the CD44 molecule was significantly increased in $T$ cells from the rheumatoid synovial fluid relative to $T$ cells from peripheral blood. CD44 expression on non-T cells did not appear to differ between the rheumatoid synovial leucocytes and peripheral blood mononuclear cells. Significantly, peripheral blood CD44 expression did not appear to be increased relative to that in normal individuals. Similar findings were obtained in respect of LFA-1 expression: the uniphasic pattern of expression was detected predominantly in the rheumatoid synovial fluid. Our data are consistent with the hypothesis that $\mathrm{CD} 44^{\mathrm{hi}}$ and LFA-1 uniphasic cells selectively accumulate in rheumatoid synovial fluid. However, it is also possible that local activation of these lymphocytes in situ may be responsible for enhanced expression. For example, we have demonstrated that in vitro activation of lymphocytes results in upregulation of both LFA-1 and CD44, as has previously been described. ${ }^{1}$ We have found that $\mathrm{T}$ cell culture in the absence of mitogens is sufficient to upregulate CD44 on T lymphocytes, suggesting that interaction with the matrix and with other $T$ cells rather than direct activation may result in CD44 upregulation.

The expression of CD44 on synovial fluid cell populations correlated with the percentage of lymphocytes expressing the activation markers IL-2R, M21C5, and M2B3; however, transferrin receptor expression did not correlate with CD44 expression. M21C5 and M2B3 are integral membrane proteins which are expressed on mitogen activated T cells. ${ }^{11} 12$ These studies demonstrate for the first time that expression of these activation antigens may be increased in an inflammatory condition. However, it is unclear if cells with a high density of CD44 preferentially accumulate in the rheumatoid synovial fluid, or if expression of CD44 is upregulated at the site of tissue injury. The relative paucity of expression of activation markers might suggest the former, but definitive confirmation would require in vivo experiments which are ethically and technically difficult. The relative contribution of CD44 to homing to synovium is also unclear. Synovial fluid T lymphocytes demonstrate increased binding to both E-selectin and vascular cell adhesion molecule- $1 .{ }^{14}$ In addition, rheumatoid synovial fluid lymphocytes bind to fibronectin using the vascular leucocyte antigen-5 integrin. ${ }^{15} 16$ It is currently unclear what the relevant contribution of each of these interactions is to lymphocyte migration to the inflamed synovium.

Memory $\mathrm{T}$ lymphocytes as defined by CD45RO expression are found to have high expression of CD44. ${ }^{17}$ However, it appears that increased expression of CD44 on memory cells occurs after the acquisition of the memory phenotype. ${ }^{17}$ Increased expression of CD44 does not in itself necessarily indicate a memory phenotype, as expression of this molecule may be upregulated by cytokines, including tumour necrosis factor (TNF) $\alpha$ and interferon gamma. ${ }^{18}$ There appears to be no difference in the mean fluorescence intensity of LFA-1 expression in memory $\mathrm{T}$ cells. ${ }^{19}$ As in the current study, LFA-1 expression on memory cells $\left(\mathrm{CD} 45 \mathrm{RA}^{-}\right)$appears to occupy a single peak intermediate between biphasic peaks seen on CD45RA ${ }^{\text {hi }}$ and CD45RA ${ }^{\text {lo }}$ cells. However, expression is increased on lymphocyte activation. ${ }^{19}$ Nonetheless, the rheumatoid synovial fluid contains a preponderance of memory $\mathrm{T}$ cells. ${ }^{20}$ Memory lymphocytes from the rheumatoid patient have increased migratory capacities $^{21}$ and expression of high levels of CD44 may be one mechanism by which homing of activated or memory lymphocytes to the rheumatoid synovium occurs.

It has been known for some time that the molecular mass of the CD44 molecule is variable, depending on the level of glycosylation of the core peptide. However, it has been demonstrated that there are a number of different core peptides, ${ }^{22}$ and that expression of individual isoforms on tumour cells may result in a more invasive phenotype..$^{23}$ It is possible that expression of individual isoforms on $T$ cells, in addition to the increased density, may play a role in the invasive properties of a homing $T$ cell. We have not found evidence of high variants of this molecule by Western blotting. However, we cannot exclude the possibility that the detection system is not sufficiently sensitive to detect small quantities of these isoforms. The molecular weight of CD44 is reduced on rheumatoid synovial fluid. 
This reduction is consistent with deglycosylation, or possibly dephosphorylation, and could potentially change ligand binding/ homing properties of the molecule. In this regard it is notable that the LFA-1 molecule becomes activated on dephosphorylation, with resultant increases in homotypic aggregation. ${ }^{24}$

The CD44 molecule is also a signalling molecule with potential for signalling production of cytokines including TNF, ${ }^{25}$ and for signalling upregulation of other adhesion molecules such as LFA-1. ${ }^{26}$ Upregulation of LFA-1 may potentiate $T$ cell activation ${ }^{27}$ and may also facilitate either generation of cytoskeletal changes associated with a locomotion associated phenotype ${ }^{28}$ or, alternatively, homotypic aggregation. ${ }^{29}$ Thus interaction with putative ligands within the rheumatoid synovium may result in the amplification of the local inflammatory response. In addition, increased soluble CD44 has been demonstrated in synovial fluid, possibly related to release from the synovial membrane, and this, in addition to increased tissue CD44, could potentially have a consumptive effect on synovial fluid hyaluronic acid, with resultant decrease in synovial fluid viscosity. ${ }^{30}$ Thus this molecule might contribute to joint damage in rheumatoid patients in a number of ways, either directly or indirectly through effects on other adhesion molecules. Soluble hyaluronate has been reported to depress $T$ cell proliferative responses, possibly by binding to CD $44 ;^{31}$ soluble CD44 complexed to liposomes also depressed $\mathrm{T}$ cell proliferative responses. ${ }^{30}$ Hence, it cannot be assumed that the increased CD44 is associated with functional activation of synovial fluid lymphocytes. Further studies are required to determine the mechanisms involved in the reduction of molecular mass of CD44 in RA synovial fluid. In particular, the development of monoclonal antibodies to peptides specific to individual CD44 exons should facilitate assessment of exon utilisation in this condition.

This work was supported by a grant from the Arthritis Foundation of Ireland. DK is a Wellcome Senior Fellow in Clinical Science; $\mathrm{MBO}$ is a Pew Scholar; $\mathrm{AL}$ is supported by a grant from the Cancer Research Advancement Board.

1 Springer T A. Adhesion receptors of the immune system. Nature 1990; 51: 425-33.

2 Butcher E C. Cellular and molecular mechanisms that direct leukocyte traffic. Am $\mathcal{F}$ Pathol 1990; 136: 3-11.

3 Chin Y-H, Cal J-P, Johnson K. Lymphocyte adhesion to cultured Peyer's patch high endothelial venule cells is mediated by mediated by organ-specific homing receptors and can be

4 van Epps D E, Potter J, Vachula M, Smith C W, Anderson D C. Suppression of human lymphocyte chemotaxis and transendothelial migration by anti-LFA-1 antibody. $\mathcal{F}$ Immunol 1989; 143: 3207-13.

5 Jalkanen S T, Bargatze R F, de los Toyos J, Butcher E C Lymphocyte recognition of high endothelium: Antibodies to distinct epitopes of an 85-95 kD glycoprotein antigen differentially inhibit lymphocyte binding to lymph nodes, mucosal or synovial endothelial cells. $f$ Cell Biol 1987; 105: 983-90.

6 Omary M B, Trowbridge I S, Letarte M, Kagnoff M F, Isacke C M. Structural heterogeneity of human Pgp-1 and its relationship with p85. Immunogenetics 1988; 27: $460-4$
7 Murakami S, Miyake $\mathrm{K}$, June $\mathrm{C} \mathrm{H}$, Kincade $\mathrm{P} W$, Hodes R J. IL-5 induces a Pgp-1 (CD44) bright B cell subpopulation that is highly enriched in proliferative and Ig secretory activity and binds to hyaluronate. $\mathcal{F}$ Immunol 19 secretory activity and

8 Jackson D G, Buckley J, Bell J I. Multiple variants of the human lymphocyte homing receptor $\mathrm{CD} 44$ generated by insertions at a single site in the extracellular domain. $\mathcal{F} \mathrm{Bio}$ Chem 1992; 267: 4732-9.

9 Sy M S, Guo Y-J, Stamenkovic I. Distinct effects of two CD44 isoforms on tumor growth in vivo. $\mathcal{F}$ Exp Med 1991 174: 859-66.

10 Takahashi H, Soderstrom K, Nilsson E, Kiessling R, Patarroyo M. Integrins and other adhesion molecules on lymphocytes from synovial fluid and peripheral blood of rheumatoid arthritis patients. Eur $\mathcal{f}$ Immunol 1992; 22: 2879-85.

11 Omary M B, Kelleher D, Kagnoff M F. An 80-85 kilodalton human phosphoglycoprotein associated with cell activation. F Immunol 1988; 141: 3492-7.

12 Omary M B, DeGrandpre L, Varki N M, Kagnoff M F. A tyrosine sulfated human glycoprotein with an unusual cell distribution. Mol Immunol 1992; 29: 9-19.

13 Pitzalis C, Kingsley G, Murphy J, Panayi G. Abnormal distribution of the helper-inducer and suppressor-inducer T-lymphocyte subsets in the rheumatoid joint. Clin Immunol Immunopathol 1987; 45: 252-8.

14 Postigo A A, Garcia-Vicuna R, Diaz-Gonzalez F, et al. Increased binding of synovial T-lymphocytes from rheumatoid arthritis to endothelial-leukocyte adhesion molecule-1 (ELAM-1) and vascular cell adhesion molecule-1 (VCAM-1). F Clin Invest 1992; 89: 1445-52.

15 Garcia-Vicuna R, Humbria A, Postigo A A, et al. VLA family in rheumatoid arthritis: evidence for in vivo regulated adhesion of synovial fluid $T$ cells to fibronectin through VLA-5 integrin. Clin Exp Immunol 1992; 88: 435-41.

16 Rodriguez R M, Pitzalis C, Kingsley G H, Henderson E, Humphries M J, Panayi G S. T lymphocyte adhesion to fibronectin (FN): a possible mechanism for $T$ cell accumulation in the rheumatoid joint. Clin Exp Immunol 1992; 89: 439-45.

17 Prince H E, York J, Jensen E R. Phenotypic comparison of the three populations of human lymphocytes defined by the three populations of human lymphocytes defined by 145: 254-62.

18 Mackay C R, Terpe H J, Stauder R, Marston W L, Stark H, Gunthert U. Expression and modulation of CD44 variant isoforms in humans. $f$ Cell Biol 1994; 124: 71-82.

19 Hviid L, Odum N, Theander T G. The relation between T-cell expression of LFA-1 and immunological memory. Immunology 1993; 78: 237-43.

20 Thomas R, McIlraith M, Davis L S, Lipsky P E. Rheumatoid synovium is enriched in CD45RB dim mature memory $T$ cells that are potent helpers for B cell mature memory T cells that are potent helpers for

21 Cush J J, Pietschmann P, Oppenheimer-Marks N, Lipsky P E. The intrinsic migratory capacities of memory $\mathrm{T}$-cells contributes to their accumulation in rheumatoid synovium. Arthritis Rheum 1992; 35: 1434-44.

22 Dougherty G J, Lansdorp P M, Cooper D L, Humprhies R K. Molecular cloning of CD44R1 and CD44R2, two novel isoforms of the human CD44 lymphocyte 'homing' receptor expressed by hemopoietic cells. 7 Exp Med 1991; 174: 1-5.

23 Arch R, Wirth K, Hofmann M, et al. Participation in normal immune responses of a metastasis-inducing splice variant immune responses of a metastasis-ind

24 Hedman $\mathrm{H}$, Lundgren E. Regulation of LFA-1 avidity in human B-cells; requirements for dephosphorylation events during high avidity ICAM-1 binding. F Immunol 1992; 149: 2295-9.

25 Chong A S, Boussy I A, Graf L H, Scuderi P. Stimulation of IFN-gamma, TNF-alpha and TGNF-beta secretion in IL-2 activated T cells: costimulatory roles for LFA-1, LFA-2, CD44 and CD45 molecules. Cell Immunol 1992; 144: 69-79.

26 Koopman G, van Kooyk Y, de Graaff M, Meyer C J L M, Figdor C G, Pals S T, Triggering of the CD44 antigen on $\mathrm{T}$ lymphocytes promotes $\mathrm{T}$ cell adhesion through the on T lymphocytes promotes T cell adhesion thro

27 Wacholtz M C, Patel S S, Lipsky P E. Leukocyte functionassociated antigen 1 is an activation molecule for human T cells. $\mathcal{F}$ Exp Med 1989; 170: 431-48.

28 Kelleher D, Murphy A Cullen D. Leukocyte functionassociated antigen 1 (LFA-1) is a signaling molecule for cytoskeletal changes in a human $\mathrm{T}$ cell line. Eur $\mathcal{f}$ Immunol 1990; 20: 2351-4.

29 Dustin M L, Springer T A. T-cell receptor cross-linking transiently stimulates adhesiveness through LFA-1. Nature 1989; 341: 619-24.

30 Haynes B F, Hale L P, Patton K L, Martin M E, McCallum R M. Measurement of an adhesion molecule as an indicator of inflammatory disease activity. Arthritis Rheum 1991; 34: 1434-43.

31 Anastassiades T, Robertson W. Modulation of mitogendependent lymphocyte stimulation by hyaluronic acid. fR Reumatol 1984; 11: 734-9. 